\title{
The BRCAI/2 pathway prevents hematologic cancers in addition to breast and ovarian cancers Bernard Friedenson*
}

Address: Department of Biochemistry and Molecular Genetics, College of Medicine, University of Illinois Chicago, 900 South Ashland Ave, Chicago, IL 60607, USA

Email: Bernard Friedenson* - molmeddoc@yahoo.com

* Corresponding author

Published: 6 August 2007

BMC Cancer 2007, 7:152 doi:10.1 |86/|47|-2407-7-152
Received: 17 November 2006

Accepted: 6 August 2007

This article is available from: http://www.biomedcentral.com//47/-2407/7//52

(C) 2007 Friedenson; licensee BioMed Central Ltd.

This is an Open Access article distributed under the terms of the Creative Commons Attribution License (http://creativecommons.org/licenses/by/2.0), which permits unrestricted use, distribution, and reproduction in any medium, provided the original work is properly cited.

\begin{abstract}
Background: The present study was designed to test the hypothesis that inactivation of virtually any component within the pathway containing the BRCAI and BRCA2 proteins would increase the risks for lymphomas and leukemias. In people who do not have BRCAI or BRCA2 gene mutations, the encoded proteins prevent breast/ovarian cancer. However BRCAI and BRCA2 proteins have multiple functions including participating in a pathway that mediates repair of DNA double strand breaks by error-free methods. Inactivation of BRCAI, BRCA2 or any other critical protein within this "BRCA pathway" due to a gene mutation should inactivate this error-free repair process. DNA fragments produced by double strand breaks are then left to non-specific processes that rejoin them without regard for preserving normal gene regulation or function, so rearrangements of DNA segments are more likely. These kinds of rearrangements are typically associated with some lymphomas and leukemias.
\end{abstract}

Methods: Literature searches produced about 2500 epidemiology and basic science articles related to the BRCA pathway. These articles were reviewed and copied to a database to facilitate access. Meta-analyses of statistical information compared risks for hematologic cancers vs. mutations for the components in a model pathway containing BRCAI/2 gene products.

Results: Deleterious mutations of genes encoding proteins virtually anywhere within the BRCA pathway increased risks up to nearly 2000 fold for certain leukemias and lymphomas. Cancers with large increases in risk included mantle cell lymphoma, acute myeloid leukemia, acute lymphocytic leukemia, chronic lymphocytic leukemia, and prolymphocytic leukemia. Mantle cell lymphoma is defined by a characteristic rearrangement of DNA fragments interchanged between chromosomes II and I4. DNA translocations or rearrangements also occur in significant percentages of the other cancers.

Conclusion: An important function of the BRCA pathway is to prevent a subgroup of human leukemias and lymphomas that may involve non-random, characteristic gene rearrangements. Here, the genetic defect in BRCA pathway deficiencies is a chromosomal misrepair syndrome that may facilitate this subgroup of somatic cancers. Inactivation of a single gene within the pathway can increase risks for multiple cancers and inactivation of a different gene in the same pathway may have similar effects. The results presented here may have clinical implications for surveillance and therapy. 


\section{Background}

BRCA1 and BRCA2 proteins are thought to be essential to prevent breast/ovarian cancer largely because of the high lifetime risks faced by carriers of mutations in the corresponding genes. More modest increases in risk for other cancers have also been noted [1-5]. Basic science studies find multiple biologic functions for BRCA1 and BRCA2 proteins [6-15], including participating within a pathway that mediates error-free repair of DNA double strand breaks by homologous recombination [15].

Fig. 1 summarizes a model for this error-free double strand break repair pathway (based on reference [16]). BRCA1 and BRCA2 gene products are placed within a sequence encompassing the MRE11, Rad50 and NBS1 complex (MRN complex), ATM, CHEK2, BRCA1, BRCA2, and Fanconi anemia proteins. For the purposes of this paper, this model will be referred to as the "BRCA pathway."

A critical protein function lost from anywhere within this error-free repair BRCA pathway may force repair of DNA double strand breaks by lower fidelity, error prone methods. Risks for cancers mediated by such errors should then greatly increase. Lymphomas and leukemias can be associated with large gene rearrangements, which can be pictured as arbitrary rejoining of broken DNA fragments. For example, almost all mantle cell lymphomas have a characteristic interchange between pieces of chromosomes 11 and $14[\mathrm{t}(11 ; 14)(\mathrm{q} 13 ; \mathrm{q} 32)]$. In some leukemias, the make-up of a fusion protein may bear witness to other abnormal repairs [e.g. [17]]. Error-tolerant repair may also leave other signs such as in the acute myeloid leukemias, where there may be evidence of abnormal gene fusions, duplications, inversions, deletions or reciprocal translocations [18]. The present study was designed to test the hypothesis that inactivation of a critical component of the BRCA pathway would favor gene rearrangements that underlie some lymphomas and leukemias. The results show that risks for a subset of leukemias and lymphomas increase up to nearly 2000 fold. The results may have clinical implications for surveillance and chemotherapy.

\section{Methods}

The study was designed to review the risks for leukemias and lymphomas associated with a deleterious mutation within a prototype BRCA pathway (Fig. 1) for error-free double strand break repair. The purpose of this article is not to examine functionality of specific gene variants, but rather to examine the effect of loss of gene function anywhere within a testable pathway on risk for specific hematologic cancers. For many of the studies examined, especially case series, the exact genetic variant is unknown but loss of gene function (regardless of the reason) was confirmed by other means (e.g. RNA, protein or other

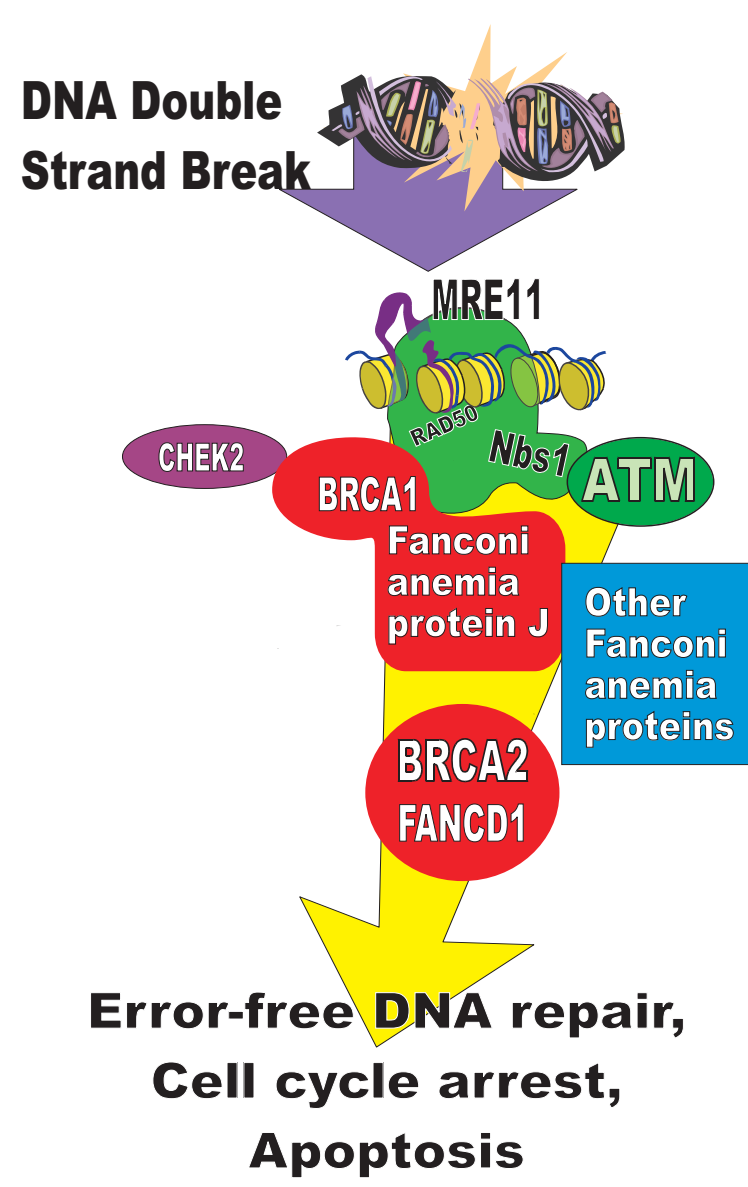

Figure I

Schematic model for the "error-free" BRCA double strand break repair pathway Brief overview of components within the BRCA pathway used here as a working model that was tested here. The model is based largely on reference 16 . BRCA2 is the same as FANCDI and the interaction between BRCAI and Fanconi anemia protein $J$ is shown. While the gene products shown represent the over-all pathway, "errorfree" double strand break repair by homologous recombination undoubtedly involves other proteins but the discussion is limited to those shown. Not shown are details of the 13 Fanconi anemia gene products and additional components including EMSY, a whole family of RAD5 I related proteins, DCC, cohesins and accessory proteins. Deficiency states may be rare or unknown for these additional proteins and large epidemiologic studies are uncommon. Other protein kinases related to ATM carry out similar functions in response to other genotoxic stresses, and some of them collaborate with ATM. Proteins within the pathway also interact with other branches of the DNA damage response and with further proteins. 
tests). Genes examined were ATM, NBS1, MRE11, BRCA1, BRCA2, Fanconi anemia genes usually studied as a group including 13 known genes, and CHEK2.

PubMed, PubMed Central, Google, and Google scholar searches were conducted to collect relevant research articles related to the model BRCA pathway. These searches were for epidemiology studies published within the last $\sim 20$ years and basic science articles published within the past 15 years. About 2500 articles were reviewed and copied to a database to facilitate search and further review. Where available statistical information permitted, metaanalysis with heterogeneity testing was conducted comparing cancer risk vs. deleterious mutation of a pathway gene.

Case-control, cohort and prevalence studies were reviewed. Data from studies that measured cancer incidences associated with epigenetic modification of pathway genes and/or alterations in protein or mRNA levels were also included. Epidemiologic studies were excluded in whole or in part if they did not provide required data or permit calculation of required information or if they were superseded or subsequently invalidated. The rarity of mutations in some molecules limited data available and limited the analysis of some BRCA pathway components. As far as possible, statistical analyses were limited to gene variants either known to eradicate normal protein function or to severely lower normal levels. All the mutations were spontaneously occurring and/or inherited except for therapy related (somatic) inactivation of BRCA1 in acute myeloid leukemia (AML). To verify that therapy related disease did not bias the results it was compared to data for primary AML.

Epidemiologic data was tabulated as odds ratios or relative risks: for ATM associations with NHL as MCL, with ALL, CLL, and PLL; for Fanconi anemia gene associations (13 known genes) with primary AML, with leukemia before age 15 and with ALL; for BRCA1 associations with primary and therapy related AML and with CML; for BRCA2 associations with AML, ALL and CLL; for NBS1 associations with lymphomas, ALL and NHL; and for CHEK 2 associations with CLL.

The DerSimonian-Laird random effects model[21] was used throughout since it relaxes the assumption of a common effect due to mutation. This may be more appropriate here than fixed effects models since inactivating mutations can in theory have different targets with different effect sizes. However, the uncertainty bounds for random effects are more conservative and often larger. When at least three studies were available, meta-analysis was performed. For the 9 studies available for ATM mutations in MCL, potential methodological confounders were ruled out by generating subgroups without the potential confounder. Statistical associations were compared to independent basic science experiments and to basic science theory.

Data from the NCI Surveillance Epidemiology and End Result (SEER) program was used to compare incidences in the general population for the approximate age ranges in Fanconi anemia groups. The NCI "DevCan" program was used to calculate cumulative control incidences for cancers affecting Fanconi anemia patients. Population data in DevCan came from 10,000 patients using 1999-2001 figures, but was matched as closely as possible to patient numbers in the Fanconi anemia study. Relative risks and confidence intervals for random effects models were then calculated by StatsDirect and RevMan. In Fanconi anemia, death, bone marrow transplant, AML and solid tumors censor or alter the natural history of other conditions but competing risk models were not used.

The prevalence of ATM mutation heterozygotes in the general population is widely cited as $0.3 \%$ to $1 \%$. The incidence of biallelic mutations which are required to cause the hereditary disease A-T is much smaller (3/million to $11 /$ million) $[22,23]$. Use of any value within this range as a control would give much larger risks. However, a population prevalence of $1 \%$ for ATM mutations was used to prevent overstating differences from the general population.

Heterogeneity was calculated as non-combinability of odds ratios by the Breslow-Day method, from the inconsistency statistic[24], by a moment based method and graphically from L'Abbe plots. None of the meta-analyses presented showed evidence for heterogeneity by these criteria. Chi-square tests on combined odds ratios were performed. Bias was assessed using the method of Egger and by inspecting funnel plots for asymmetry[25]. There was no statistical evidence of publication bias for summary estimates (results not shown).

A general limitation of meta-analysis is that access to original data is limited or the data is so old that some calculations in publications are impossible to reproduce. Fortunately, some articles used in meta-analyses contained both raw and final calculated data. This enabled control experiments to check the validity of calculations based on raw data. Testing raw instead of final data gave no or very small errors as confirmed dozens of times. To rule out computer program errors, the RevMan program from the Cochrane Review Group was used to verify some calculations made by StatsDirect. Microsoft Excel with the data-analysis add-in was used for some calculations. 


\section{Results}

The present study was designed to test the hypothesis that inactivation of virtually any component within the BRCA pathway would increase risks for lymphomas and leukemias. Risks were summarized [see Additional file 1] for leukemias and lymphomas vs. mutations or aberrations at numerous steps within the model pathway in Figure 1. Each of the genes within the BRCA pathway is considered below. The conclusion emerges that inactivation of any of these genes greatly increases risks for a subgroup of leukemias and lymphomas. This subgroup includes (B-cell) mantle cell lymphoma (MCL), acute myeloid leukemia (AML), T-cell acute lymphocytic leukemia (T-ALL), chronic lymphocytic leukemia (B-CLL) and T-cell prolymphocytic leukemia (T-PLL). The large increases in risk suggest that preventing these diseases must be an important physiologic function of the complete BRCA pathway. The results also suggest a mechanism for this function.

\section{Inactivation of the BRCA pathway gene ATM favors a translocation associated with mantle cell lymphoma} 9 studies of the incidence of ATM mutations in MCL from a total of 363 patient samples were summarized [see Additional file 1]. Meta-analysis seemed appropriate initially because all the studies found very strong odds ratios for an ATM-MCL association, so all 9 studies have the same general pattern (criteria used by the Cochrane Review group). Combining the 9 studies then as described in Methods [21-25], gave 70.26 [95\% CI = 34.59-142.72] as the minimum odds ratio that a mantle cell lymphoma contains an ATM mutation (Table 1 ). The $\mathrm{chi}^{2}$ test value that the pooled odds ratio differs from 1 was $138.30, \mathrm{P}<0.0001$. No significant heterogeneity was found by multiple criteria given in Methods but there are only 9 estimates based on 363 people, a comparatively small pooled population.

Additional statistical confirmation that MCL is associated with ATM mutation was obtained for the data used. The product-moment linear correlation coefficient was calculated for total experimental samples with MCL vs. experimental samples with ATM mutation. The correlation coefficient value was 0.95 indicating a strong association.

The translocation $\mathrm{t}(11 ; 14)(\mathrm{q} 13 ; \mathrm{q} 32)$ is present in almost all mantle cell lymphomas[19,20]. This translocation is consistent with the misrepair of a double strand break. The MCL tumors associated with this translocation corre-

Table I: Summary of statistical associations for leukemias and lymphomas with BRCA pathway mutations

\begin{tabular}{|c|c|c|c|}
\hline Cancer & Gene mutation/polymorphism & $\begin{array}{l}\text { Data from studies with } 95 \% \text { confidence } \\
\text { intervals in brackets [see Additional file I] }\end{array}$ & $\begin{array}{l}\text { Combined values from meta- } \\
\text { analysis ( } 3 \text { or more studies) }\end{array}$ \\
\hline $\mathrm{MCL}$ & ATM & $\begin{array}{l}O R=123.75[18.84-5056.6] \\
O R=74.25[9.34-3203.5] \\
O R=297[23.49-1311.9] \\
O R=83.25[12.9-3408.7] \\
O R=81.00[9.11-3582.4] \\
O R=25.67[3.66-1095.9] \\
O R=57.32(7.25-2490.3) \\
O R=44(3.57-2186.4) \\
O R=44(5.85-1898.9)\end{array}$ & $\mathrm{OR}=70.26[34.59-\mid 42.72]$ \\
\hline Lymphomas & NBSI & $R R=1860[C \mid=972.3-3467]$ & \\
\hline PLL & ATM & $\begin{array}{l}O R=84.15[11.43-3549.9] \\
O R=165.00[19.51-7007.2] \\
O R=198[19.02-8662]\end{array}$ & $O R=137.1 \mid[39.68$ to 473.76$]$ \\
\hline ALL & ATM & $\begin{array}{l}\mathrm{OR}=16.16[2.04-724.3] \\
\mathrm{OR}=25.55[3.14-1144.6] \\
\mathrm{OR}=2.72[0.86-10.1]\end{array}$ & $\mathrm{OR}=17.98[5.37-60.18]$ \\
\hline ALL & Fanconi anemia genes & $\begin{array}{l}R R=13.26[4.11-42.68] \\
R R=10.76[3.61-32.03]\end{array}$ & \\
\hline ALL & NBSI & $\mathrm{OR}=1.85[\mathrm{Cl}=1.42-2.25]$ & \\
\hline Leukemia before age I5 & Fanconi anemia genes & $\begin{array}{l}R R=227.4[170.8-302.1] \\
R R=127.4[95.21-\mid 70.2]\end{array}$ & \\
\hline CLL & ATM & $\begin{array}{l}\mathrm{OR}=46.59[6.59-1972.5] \\
\mathrm{OR}=15.97[1.66-762.5] \\
\mathrm{OR}=13.83[2.11-580.4]\end{array}$ & $O R=21.91[6.57$ to 73.09$]$ \\
\hline CLL & CHEK2 (II57T) & $\mathrm{OR}=14.83[1.85$-infinite $]$ & \\
\hline CLL & $\mathrm{BRCA} 2(\mathrm{~N} 372 \mathrm{H})$ & $\mathrm{OR}=1.45[1.13-1.86]$ & \\
\hline AML & Fanconi anemia genes & $\begin{array}{l}R R=723.4[385.7-1355.8] \\
R R=684.8[371.6-1261.8] \\
R R=818.2[2.37-287,689]\end{array}$ & $R R=703.35[363.7-1354.5]$ \\
\hline AML & BRCAI & Association discussed in text & \\
\hline
\end{tabular}


late with loss of ATM function within the BRCA pathway [Table 1 and Additional file 1, columns 5 and 6].

\section{ATM mutation: evidence for association with the leukemias T-ALL, B-CLL, and T-PLL}

There are very high odds ratios for an association of an ATM deficit not only with MCL, but also with T-ALL, BCLL, and T-PLL (Table 1). Substantial percentages of any of these diseases associate with misrepair of some double strand break leading to gene rearrangement or deletion within an affected hematopoietic cell lineage. Fusion proteins and/or gene rearrangements have been documented in about $30 \%$ of 2367 children with ALL [26], in 11\% of B-CLL [27] and in high percentages of atypical CLL with poor prognosis[28]. Table 1 and Additional file 1 also show that ALL and CLL can be associated with any of several BRCA pathway malfunctions. Table 2 summarizes independent information [29-43,15] corroborating high risks for leukemias and lymphomas associated with ATM deficits or with other BRCA pathway abnormalities.

T-PLL is a rare malignant proliferation of post-thymic Tcells, usually with an aberrant T-cell receptor rearrangement that activates oncogenes. Data showing an association between T-PLL and ATM mutation are more limited than data for ATM associations with the other diseases. Nonetheless depending on the study, there was an ATM mutation in $46-66 \%$ of 77 tested T-PLL patients [see Additional file 1, columns 5 and 6]. The association is statistically significant but the confidence intervals are broad (Table 1). To verify this association, T-PLL risks were then considered in ataxia-telangiectasia (A-T) patients who inherit biallelic mutations in ATM. A-T patients have a $10 \%$ risk for leukemias and lymphomas which is about

Table 2: Independent evidence corroborating associations between a subset of hematologic cancers and mutations in BRCA pathway genes

\begin{tabular}{|c|c|c|c|}
\hline Cancer/abnormality & Gene mutated & Evidence & Reference \\
\hline Leukemia, NHL & ATM & $\begin{array}{l}56 \text { patients with } \mathrm{A}-\mathrm{T} \text { have standardized incidence ratio for } \\
\text { leukemia and } \mathrm{NHL} \text { of } \mathrm{I} / 3(\mathrm{Cl}=4 \mathrm{I}-246)\end{array}$ & 30 \\
\hline Thymomas, lymphoblastic lymphomas & ATM & $\begin{array}{l}\text { Atm deficient mice are immunodeficient with a high incidence of } \\
\text { thymomas or lymphoblastic lymphomas }\end{array}$ & 30 \\
\hline PLL, ALL and B-CLL & ATM & $\begin{array}{l}\text { PLL, ALL and B-CLL tumors have cytogenetic and immunologic } \\
\text { similarities to MCL. }\end{array}$ & $30,31$. \\
\hline T-PLL & ATM & $\begin{array}{l}\text { A-T patients have biallelic mutations in ATM and they develop } \\
\text { stable clones that progress to T-PLL-like disease }\end{array}$ & 32 \\
\hline B-CLL & ATM & $\begin{array}{l}\text { ATM mutant B-CLL tumors have a proven defect in the repair of } \\
\text { ionizing radiation induced damage, a function normally mediated } \\
\text { by the BRCA pathway. ATM phosphorylates BRCAI after gamma } \\
\text { radiation induced DNA damage. }\end{array}$ & 29 \\
\hline Myeloid leukemias & FANCDI & $\begin{array}{l}\text { FANCDI is the same as BRCA2 and a FANCDI/BRCA2 biallelic } \\
\text { defect associates with leukemias that are much more likely to be } \\
\text { myeloid than leukemias that develop in those with normal } \\
\text { FANCDI/BRCA2. Myeloid leukemias have increased activity of } \\
\text { the non-homologous end joining pathway, the less specific } \\
\text { alternative to the BRCA pathway. }\end{array}$ & 37 \\
\hline Double strand breaks & Fanconi anemia all types & $\begin{array}{l}\text { All Fanconi anemia cells exhibit frequent spontaneous visible } \\
\text { chromosome breaks }\end{array}$ & $34-37$ \\
\hline Gross chromosomal rearrangements & Brca2 & $\begin{array}{l}\text { Murine } \mathrm{Brca} 2 \text { is essential to suppress gross chromosomal } \\
\text { rearrangements such as translocations after chromosome } \\
\text { breakage. Mouse cells with truncated } \mathrm{Brca} 2 \text { accumulate } \\
\text { chromosome breaks and aberrant chromatid exchanges. }\end{array}$ & 15,38 \\
\hline Homologous recombination repair & FANCJ (BRCAI) & $\begin{array}{l}\text { BRCAI interacts with FANCJ. Homologous recombination repair } \\
\text { stimulated by double strand breaks is compromised both in } \\
\text { FANCJ deficient cells and in cells with BRCAI mutations that } \\
\text { preclude FANCJ interaction. }\end{array}$ & 39,40 \\
\hline Acute promyelocytic leukemia & BRCAI & $\begin{array}{l}\text { BRCAI was found to co-localize with the promyelocytic leukemia } \\
\text { protein }(\mathrm{PML}) \text { in promyelocytic nuclear bodies that function in } \\
\text { heterochromatin remodeling at the } \mathrm{G} 2 \text { phase and } \mathrm{PML} \text { protein } \\
\text { plays an essential role in the organization of the ionizing radiation } \\
\text { induced DNA repair complex. }\end{array}$ & 41,42 \\
\hline $\begin{array}{l}\text { Thymoma, T-cell development, } \\
\text { chromosomal abnormalities }\end{array}$ & Brca2 & $\begin{array}{l}\text { Mice homozygous for a truncating mutation in Brca2 surviving to } \\
\text { adulthood die from thymic lymphoma. BRCA2 regulates RAD5 I } \\
\text { recombinase which is essential in dividing cells. Mice carrying a T- } \\
\text { cell specific disruption of the Brcal gene display markedly } \\
\text { impaired T-lymphocyte development and proliferation with } \\
\text { increased chromosomal abnormalities. }\end{array}$ & 43,44 \\
\hline
\end{tabular}


100 fold higher than in the general population. In A-T there is a recurrent malignancy similar to T-PLL with a similar course, a similar immunophenotype, and similar cytogenetics [reference [32] and Table 2]. T-PLL occurs at high frequency in A-T families compared to non A-T families[33]. These considerations support the association between ATM mutations and T-PLL.

In some cases, there is no truly reliable way to distinguish somatic from inherited mutations in the BRCA pathway. It is unlikely that this biases the results. The first row in Table 2 gives the risk for some leukemias and lymphomas in A-T patients. Risks for A-T patients are similar to those summarized in Table 1 for ATM mutations in people who do not have hereditary A-T [also see Additional file 1]. Somatic BRCA1 data can also be compared to that for the hereditary disease Fanconi anemia because BRCA1 interacts with the Fanconi protein FANCJ. Therapy related inactivation of BRCA1 (preventing its interaction with FANCJ) causes risks for AML comparable to risks for AML due to hereditary Fanconi anemia (see below).

\section{Fanconi Anemia genes within the BRCA pathway and early leukemias}

I also examined potential associations between hereditary Fanconi anemia gene mutations and risk of hematologic cancers. Results were available from about 80 years of published data in Fanconi anemia databases [34-36]. Data exists from a relatively large number of patients in 3 summary studies. The Fanconi anemia studies each report very large hazard ratios for early leukemias and calculated relative risks are also high [see Additional file 1]. Fanconi anemia patients have a relative risk of 703.35 for AML as calculated by meta-analysis (Table 1 ). Frequent spontaneous chromosome breaks and gross-chromosomal rearrangements are visible in Fanconi anemia cells (Table 2), consistent with large increases in risk for cancers mediated by chromosome rearrangements. Some data predates the ability to identify individual Fanconi mutations. This merged data was justified for use here because of the close interactions and relationships among Fanconi proteins (Figure 1).

\section{$B R C A I$ and $B R C A 2$ genes in the BRCA pathway and $A M L$, leukemias and lymphomas}

Independent and unrelated lines of investigation strongly implicate BRCA1 and BRCA2 deficiencies in hematologic cancers. This information is summarized below and there is additional corroborating evidence [15,37-44] in Table 2. BRCA1 deficiency is strongly associated with both de novo- and therapy related AML. 32\% (32/112) of primary AML tumors and $75 \%(16 / 21)$ of therapy related AML tumors have reduced BRCA1 gene expression [reference [45] and see Additional file 1]. In chronic myelogenous leukemia (CML) cells, BRCA1 is also down regulated, becoming nearly undetectable in leukemia cells from patients during chronic phase and blast crisis [see Additional file 1]. Deleterious BRCA2 sequence variants are over-represented in cases of T-cell Non-Hodgkins lymphoma (NHL) or CLL [see Additional file 1], consistent with a role for BRCA2 in preventing these diseases.

Relationships and critical interactions exist among BRCA1, BRCA2 and Fanconi anemia proteins(e.g. Fig. 1 and Table 2). Because of connections between Fanconi proteins and leukemias, these relationships further implicate BRCA1/BRCA2 deficits in leukemias. As an example of interactions between Fanconi anemia proteins and BRCA1/2 proteins, the Fanconi anemia protein FANCJ forms an essential complex with BRCA1. This complex brings FANCJ (together with replication protein A) into nuclear foci at the site of DNA damage. FANCJ then unwinds DNA sufficiently so that error-free repair can begin (Table 2). In kindreds who have BRCA2 (FANCD1) mutations on top of another Fanconi anemia mutation, leukemia occurs at a median age of 2.2 years instead of 13.4 years [reference [37] and Additional file 1].

Some epidemiologic studies show increased risks for leukemia/lymphoma[1] in identified BRCA1 or BRCA2 mutation carriers $[46,47]$ and in large populations eligible for mutation testing [48-53]. Family history can be used to determine eligibility for mutation testing and can estimate the likelihood that a BRCA1 or BRCA2 mutation exists within the family[1]. Rauscher et al [54] reported that family history of breast cancer increased risk due to a range of leukemia risk factors that were generally weak or non-existent when considered alone. Combined with a family history of breast cancer, ever-smoking $\left[\mathrm{RR}_{11}=2.4\right.$, $\mathrm{CI}=1.2-4.8]$, general solvent exposure $\left(\mathrm{RR}_{11}=1.9, \mathrm{CI}=\right.$ 1.1-3.4), aromatic hydrocarbon exposure $\left(\mathrm{RR}_{11}=3.8, \mathrm{CI}\right.$ $=1.1-14)$, and diagnostic ionizing radiation exposure $\left(\mathrm{RR}_{11}=2.1, \mathrm{CI}=1.2-3.8\right)$ were all associated with increased leukemia incidence. There was no increased incidence associated with any of these exposures in the absence of a family history of breast cancer[54].

\section{MREI I-Rad50-NBSI: a complex of BRCA pathway genes and lymphomas and leukemias}

Abnormalities in a complex containing the BRCA pathway proteins MRE11, Rad50 and NBS1 (MRN complex) also associate with leukemia and lymphoma. Rarely, hypomorphic mutations in MRE11 occur in individuals with "Ataxia-Telangiectasia-Like-Disorder" (ATLD). Lymphocytes from ATLD patients may carry chromosome translocations identical to lymphocytes from A-T patients[55], implying a corresponding predisposition to leukemias and lymphomas. A hypomorphic mutation of the NBS1 gene causes Nijmegan Breakage Syndrome (NBS). Patients in the International NBS study group have 
enormously elevated risks for lymphoma at ages 1-22 (RR = 1860) [see Additional file 1]. Heterozygotes have lower risks but still appear predisposed to lymphomas and leukemias [see Additional file 1]. Lymphocytes or other cells from NBS patients show increased chromosomal translocations[56].

\section{CHEK2: a BRCA pathway gene and lymphomas and leukemias}

Checkpoint kinase 2 (CHEK2) participates in the BRCA pathway by phosphorylating BRCA1, promoting cell cycle arrest, and activating DNA repair in genetically damaged cells[57]. CHEK2 may also affect risks for hematologic cancers. The CHEK2 variant I157T is significantly associated with CLL [see Additional file 1]. CHEK2 mutations were uncommon in NHL but $9 \%$ of these tumors showed either total or near-total absence of the CHEK2 protein[58]. CHEK2 alterations responsible for these low levels occur in a subset of aggressive lymphomas having a relatively high number of chromosomal imbalances[58]. CHEK2 may also have some relationship to promyelocytic leukemia (PML) because CHEK2 phosphorylates the tumor suppressor PML gene protein leading to apoptosis[59] Although the composition of nuclear bodies containing PML varies during the cell cycle, they may also contain other members of the BRCA pathway and participate in double strand break repair[60,61].

\section{Discussion}

Participation of BRCA pathway deficiencies in leukemias and lymphomas can be explained by incorporating features of overlapping theories for how cancers arise. These theories are differentiation-maturation mutations cooperating with proliferation/survival mutations, lineageaddiction or -dependency models, and the existence of "cancer stem cells" arising from an ordered sequence of phenotypically distinct stem-cell and intermediate-precursor populations [62-64]. Applying elements of these current theories helps clarify the present results as discussed below.

Some lymphomas and leukemias are defined by non-random, characteristic gene rearrangements [e.g. [65-68]] but people can have small numbers of cells containing one of these translocations that may not progress to cancer. Thus additional abnormalities are required to create cancer. According to one hypothesis[62], two kinds of gene rearrangements or other mutations cooperate to produce leukemias and lymphomas (i-ii). $i$. Gene rearrangements or other mutations that give a growth and/or survival advantage to malignant cells. ii. Gene rearrangements or other mutations that impair differentiation.

Mantle cell lymphoma (MCL) is associated here with a BRCA pathway deficit and this association is consistent with current cancer models. In almost all cases of MCL, there is a characteristic exchange of fragments between chromosome 11 and chromosome 14. The rearrangement occurs within a subset of naive pregerminal center cells in the B-cell lineage. This "MCL translocation" results in the juxtaposition of the BCL1 gene (cyclin D1) and the immunoglobulin heavy chain locus. The MCL translocation causes cyclin D1 to become overexpressed because it comes under the control of the highly active immunoglobulin gene enhancer. Overexpressed cyclin D1 then probably functions as an oncogene by accelerating cell division. This gives a growth advantage to cells containing the rearrangement. In some systems, cancer cell lines are dependent on a cyclin D1 oncogene for survival (oncogene addiction). Abnormal cells here with the cyclin D1 oncogene, have a growth advantage that makes further mutations more likely to accumulate. A BRCA pathway deficit causes an underlying deficiency in error-free repair that increases the number of abnormal cells and adds further to the chances for additional abnormalities. However, the aberrant B-cell lineage may well condition the range of mutations allowed because of embedded differentiation or developmental programs. "Atypical CLL" shares cytogenetic and immunologic features with MCL[32,69]. The same "MCL translocation" between chromosomes 11 and 14 occurs in "atypical CLL." [69], consistent with this macro-genomic alteration being restricted to the B-cell lineage.

AML is another example of a disease associated with a deficit in BRCA-pathway-mediated DNA repair. The hallmark of all AML types is a severe block in myeloid differentiation. In previous sections of this paper, Fanconi anemia patients were shown to have $>700$ fold increase in combined relative risk for AML (Table 1). In Fanconi anemia, the BRCA pathway deficiency leads to visibly increased numbers of chromosome breaks, gaps, rearrangements, and quadriradii in the presence of DNA damaging agents. This may result from a documented increase in repair by the less specific process of non-homologous end joining.

AML is the generic term for a group of myeloid leukemias that have a clonal expansion of immature myeloid progenitor stages (blasts) in the bone marrow, blood or other tissues. Different categories of AML can depend on a particular mutation event that creates a block in differentiation and the stage within the myeloid lineage when the event occurs. Translocation events, duplications, inversions, or deletions would be favored by BRCA pathway defects and they represent potential ways to create a differentiation block typical of AML. Although other types of mutation also create differentiation blocks in AML, the large increases in relative risk in Fanconi anemia suggests that gene rearrangements are important. In Fanconi anemia, translocations occur at a rate that is at least ten times 
greater than normal after exposure to ionizing radiation [70].

An example of a translocation capable of creating a differentiation block is the recurring $\mathrm{t}(3 ; 12)$ (q26;p13) translocation. In a Fanconi anemia patient, this rearrangement was present in the bone marrow at the time of initial diagnosis of myelodysplastic syndrome (often a precursor of AML). The patient had a normal constitutional karyotype but AML then developed. When acute transformation to AML occurred, cytogenetic analysis found multiple chromosome deletions and rearrangements typical of Fanconi anemia[71]. Fanconi anemia is a rare inherited disease, but the same $t(3 ; 12)$ translocation is sometimes the first and the only cytogenetic abnormality found in AML patients who do not have hereditary Fanconi anemia. This particular rearrangement is thought to predispose to AML as follows[72]. It causes overexpression of the EVI-l gene because EVI-1 becomes driven by the TEL promoter $[71,62]$. Normally EVI-1 is expressed in early myeloid progenitor cells where it helps determine whether progenitors differentiate or proliferate. Abnormal EVI-1 expression probably contributes to AML by interfering with other genes controlling the commitment to differentiate. These progenitors are designed to proliferate rapidly and then to differentiate. Failure to induce timely differentiation might result in a prolonged proliferation phase favoring the accumulation of additional cooperating events. This places the progenitors at much higher risk for leukemia [63]. A background of hereditary Fanconi anemia would greatly increase chances for gene rearrangements and deletions in progenitors both as initial and as cooperating events.

A variety of gene rearrangements due to misrepaired double strand breaks also occur frequently in other diseases associated here with BRCA pathway deficiencies. In some cases of T-PLL, one gene rearrangement deregulates the expression of the T-cell receptor. Similarly, any of several recurring chromosomal translocations can be detected in substantial numbers of cases of childhood ALL.

Defects in the BRCA pathway increase the risks for a subset of lymphomas and leukemias that are probably associated with gene rearrangements. However a BRCA pathway deficit does not cause the underlying gene rearrangements. The deficit allows more mistakes in double strand break repair, increases the numbers of cells with mistakes and then permits abnormal cells to survive.

In myeloid leukemias, certain sites may associate with up to 40 different gene partners and chromatin structural elements closely associate with such breakpoints [68]. Some of these translocations have prognostic significance. Perhaps certain chromosome regions are selected for these rearrangements because they are more actively transcribed and exposed in a transcription complex[73]. The proximity between neighboring chromosomes may also be an influence.

Some tumors [see Additional file 1] contain evidence that ATM deficiency compromises the BRCA pathway regardless of other pathways involving ATM. Gene fusions or other rearrangements often found in some of these tumors bear witness to a double strand break repaired by error-prone methods. The cancers reported here are thus primarily somatic in origin but the predisposition to misrepair of DNA breaks and chromosomal instability may be inherited. Inactivation of a single gene can increase risks for multiple cancers and inactivation of a different gene in the same pathway may have similar effects [see Additional file 1].

The deficiencies that increase risk for leukemias and lymphomas may well be helpful in understanding other cancers in BRCA1/2 mutation carriers. The involvement of BRCA pathway deficits in a subset of hematologic cancers has implications for surveillance and for therapy in hematologic and perhaps in other cancers. These deficits suggest the need for improved surveillance. They also present a vulnerability that may be exploited during therapy.

Reciprocal translocations and other chromosome rearrangements also occur in breast and in ovarian tumors[74,75]. Comparative genome hybridization has shown that human epithelial breast tumors undergo widespread gains and losses of chromosomes early in their development, correlating well with the presence of complex chromosomal rearrangements [76]. In comparing hematological and epithelial cancers in 2001, Ponder asked "Are there similar mechanisms among the more complex chromosomal changes in epithelial malignancies, or do epithelial cancers have different genetic mechanisms of development?" [77]. The data in the present paper adds the information that the same BRCA pathway can be disabled in both breast and hematological cancers, showing that further consideration of Ponder's question may be very helpful.

\section{Conclusion}

BRCA1 and BRCA2 are critical to prevent breast and ovarian cancers in mutation carriers but the proteins participate in processes that are fundamental for survival in other types of cells. The genetic defect accompanying BRCA pathway deficiencies studied here is a chromosomal misrepair syndrome. This work shows that the pathway containing BRCA1/2 gene products is essential to prevent a group of leukemias and lymphomas. The results may have clinical implications for surveillance and chemotherapy in these and perhaps in other cancers. 


\section{Abbreviations}

AML, acute myeloid leukemia; A-T, ataxia-telangiectasia; ATLD, Ataxia-Telangiectasia-Like-Disorder; ATM, ataxiatelangiectasia mutated; B-CLL, (B-cell) chronic lymphocytic leukemia; CHEK2, Checkpoint kinase 2; CI = 95\% Confidence Interval; $\mathrm{CML}$, chronic myelogenous leukemia; MCL, mantle cell lymphoma; MRN complex, complex of MRE11, Rad50 and NBS1; NBS, Nijmegan breakage syndrome; NHL, non-Hodgkins lymphoma; OR, odds ratio; PML, promyelocytic leukemia; RR, relative risk; T-ALL, T-cell acute lymphocytic leukemia; T-PLL, Tcell prolymphocytic leukemia.

\section{Competing interests}

The author(s) declare that they have no competing interests.

\section{Authors' contributions}

The author was the sole contributor.

\section{Additional material}

\section{Additional file 1}

Mutation of BRCA pathway components in leukemias and lymphomas. Summaries of case-control, cohort, and basic science research studies that provided numerical, statistical and/or patient data for BRCA pathway gene deficits vs. leukemias and lymphomas.

Click here for file

[http://www.biomedcentral.com/content/supplementary/14712407-7-152-S1.doc]

\section{Acknowledgements}

I am very grateful and wish to extend special thanks to Dr. Jack Kaplan and the UIC College of Medicine for their general support. Dr. E.P. Cohen assisted with an early helpful review. Dr. Jan Lubinski contributed invaluable critical review of the completed manuscript. Dr. Harvey Friedenson was of great help in editing the final draft. Dr. Denys Wheatley donated his valuable editorial services through Biomedes. It is a pleasure to thank biostatistician Weihua Gao, MS in the Quantitative Biomedical Sciences Program and the Quantitative Biostatistics Core of the UIC Cancer Center, for helpful discussions and review of the statistical methodology and data.

\section{References}

I. Friedenson B: BRCAI and BRCA2 pathways and the risk of cancers other than breast or ovarian. Medscape General Medicine MedgenMed 7(2): [http://www.medscape.com]. http://www.med scape.com/viewarticle/505347 June 29, 2005

2. Ford D, Easton D, Bishop DT, Narod S, Goldgar D, and the Breast Cancer Linkage Consortium: Risks of cancer in BRCA I- mutation carriers. Lancet 1994, 343:692-5.

3. Thompson D, Easton D, the Breast Cancer Linkage Consortium: Cancer Incidence in BRCA I mutation carriers. J Natl Cancer Inst 2002, I 8: | 358-| 365.

4. King M-C, Marks J, Mandell J, for The New York Breast Cancer Study Group: Breast and Ovarian Cancer Risks Due to Inherited Mutations in BRCAI and BRCA2. Science 2003, 302:643-6.

5. Walsh T, Casadei S, Coats K, Swisher E, Stray S, Higgins J, Roach K, Mandell J, Lee M, Ciernikova S, Foretova L, Soucek P, King M-C: Spectrum of mutations in BRCAI, BRCA2, CHEK2, and
TP53 in families at high risk for breast cancer. JAMA 2006, 295: $1379-1388$

6. Wang Y, Cortez D, Yazdi P, Neff N, Elledge S, Qin J: BASC, a super complex of BRCAI-associated proteins involved in recognition and repair of aberrant DNA structures. Genes Dev 2000, 14:927-39.

7. Le Page F, Randrianarison V, Marot D, Cabannes J, Perricaudet M, Feuntenn J, Sarasin A: BRCAI and BRCA2 are necessary for the transcription coupled repair of the oxidative 8-oxoguanine lesion in human cells. Cancer Res 2000, 60:5548-52.

8. Wang C-X: BRCAI: cell cycle checkpoint, genetic instability, DNA damage response and cancer evolution. Nucl Acids Res 2006, 34:|4|6-|426.

9. Bochar D, Wang L, Beniya H, Kinev A, Xue $Y$, Wang W, Kashanchi $F$, Shiekhattar R: BRCAI is associated with a human SWI/SNFrelated complex: linking chromatin remodeling to breast cancer. Cell 2000, 102:257-65.

10. Chiba N, Parvin J: Redistribution of BRCAI among four different protein complexes following replication blockage. J Biol Chem 200I, 276:38549-54.

II. Venkitaraman A: Cancer susceptibility and the functions of BRCAI and BRCA2. Cell 2002, I08: $|7|-\mid 82$.

12. Wang $\mathrm{R}-\mathrm{H}, \mathrm{Yu} \mathrm{H}$, Deng $\mathrm{C}-\mathrm{X}$ : A requirement for breast-cancerassociated gene I (BRCAI) in the spindle checkpoint. Proc Natl Acad Sci US 2004, I 0 I: I $7108-13$.

13. Jazaeri A, Chandramouli G, Aprelikova O, Nuber U, Sotiriou C, Liu ET, Ropers H, Yee C, Boyd J, Barrett C: BRCAI mediated repression of select X-chromosome genes. J Transl Med 2004, 2:32.

14. Ma Y, Katiyar P, Jones LP, Fan S, Zhang Y, Furth PA, Rosen EM: The breast cancer susceptibility gene BRCAI regulates progesterone receptor signalling in mammary epithelial cells. Mol Endocrinol 2006, 20(I): I4-34. Epub 2005 Aug 18

I5. Patel K, Yu V, Lee H, Corcoran A, Thistlethwaite F, Evans M, Colledge W, Friedman L, Ponder B, Venkitaraman A: Involvement of Brca2 in DNA repair. Molecular Cell I998, I:347-57.

16. Venkitaraman AR: A network of cancer susceptibility genes. $N$ Engl J Med 2003, 348:1917-19.

17. Zhang Y, Zeleznik-Le N, Emmanuel N, Javathilaka N, Chen J, Strissel P, Strick R, Li L, Neilly M, Taki T, Hayashi Y, Kaneko Y, Schlegelberger $B$, Rowley J: Characterization of genomic breakpoints in MLL and CBP in leukemia patients with $\mathbf{t}(\mathbf{I} \mid \mathbf{1 6})$. Genes Chromosomes Cancer 2004, 41:257-65.

18. Schichman S, Caliguri M, Strout M, Carter S, Gu Y, Canaani E, Bloomfield C, Croce C: ALL-I tandem duplication in acute myeloid leukemia with a normal karyotype involves homologous recombination between Alu elements. Cancer Res 1994, 54:4277-80.

19. Fernandez V, Hartmann E, Ott G, Campo E, Rosenwald A: Pathogenesis of mantle-cell lymphoma: all oncogenic roads lead to dysregulation of cell cycle and DNA damage response pathway. J Clin Oncol 2005, 23(26):6364-9.

20. Matutes E, Parry-Jones N, Brito-Babapulle V, Wotherspoon A, Morilla R, Atkinson S, Elnenaei M, Jain P, Giustolisi G, A'Hern R, Catovsky D: The leukemic presentation of mantle-cell lymphoma: disease features and prognostic factors in $\mathbf{5 8}$ patients. Leuk Lymphoma 2004, 45:2007-15.

21. DerSimonian R, Laird N: Meta-Analysis in clinical trials. Controlled Clin Trials 1986, 7:177-188.

22. Angele S, Romestaing P, Moullan N, Vuillame M, Chapot B, Friesen $M$ Jongmans W, Cox D, Pisani P, Gerard J-P, Hall J: ATM haplotypes and cellular response to DNA damage: association with breast cancer risk and clinical radiosensitivity. Cancer Res 2003, 63:8717-27.

23. Thompson D, Duedal S, Kirner J, McGuffog L, Last J, Reiman A, Byrd $P$, Taylor $M$, Easton $D$ : Cancer risks and mortality in heterozygous ATM mutation carriers. J Natl Cancer Inst 2005, 97:813-822.

24. Higgins J, Thompson S, Deeks J, Altman D: Measuring inconsistency in meta-analyses. Brit Med ] 2003, 327:557-60.

25. Sterne J, Gavaghan D, Egger M: Publication and related bias in meta-analysis: Power of statistical tests and prevalence in the literature. J Clin Epidemiol 2000, 53: I I 19-20.

26. Harrison C, Moorman A, Barber K, Broadfield Z, Cheung K, Harris R, Jalali R, Robinson H, Strefford J, Stewart A, Wright S, Griffiths M, Ross F, Harewood L, Martineau : Interphase molecular cytogenetic screening for chromosomal abnormalities in childhood 
acute lymphoblastic leukaemia: a UK cancer cytogenetics study. Brit J Haematol 2005, 1 29:520-30.

27. Callet-Bauchu E, Salles G, Gazzo S, Poncet C, Morel D, Pages J, Coiffier B, Coeur P, Felman P: Translocations involving the short arm of chromosome 17 in chronic B-lymphoid disorders: frequent occurrence of dicentric rearrangements and possible association with adverse outcome. Leukemia 1999, 13:460-8.

28. Avet-Loiseau H, Garand R, Gaillard F, Daviet A, Mellerin M, Robillard $\mathrm{N}$, Bouyge I, Arcot S, Batzer M, Talmant P, Harousseau J, Milpied N, Bataille R: Detection of $t(I I ; \mid 4)$ using interphase molecular cytogenetics in mantle cell lumphoma and atypical chronic lymphocytic leukemia. Genes Chromosomes Cancer 1998, 23: $175-82$

29. Stankovic T, Stewart G, Fegan C, Biggs P, Last J, Byrd P, Keenan R, Moss P, Taylor A: A-T mutated-defi cient B-cell chronic lymphocytic leukemia occurs in pregerminal center cells and results in defective damage response and unrepaired chromosomal damage. Blood 2002, 99:300-9.

30. Boultwood J: Ataxia telangiectasia gene mutations in leukemia and lymphoma. J Clin Pathol 200I, 54:5 12-16.

31. Orchard J, Garand R, Davis Z, Babbage G, Sahota S, Matutes E, Catovsky D, Thomas $P$, Avet-Loiseau H, Oscier D: A sub-set of $t(I I ; \mid 4)$ lymphoma with mantle cell features displays mutated IgVH genes and includes patients with good prognosis, non-nodal disease. Blood 2003, I 0 I (I 2):4975-8I.

32. Garand R, Goasguen J, Brizard A, Buisine J, Charpentier A, Claisse J, Duchayne E, Lagrange M, Segonds C, Troussard X, Flandrin G: Indolent course as a relatively frequent presentation in T-prolymphocytic leukaemia. Brit J Haematol 1998, 103:488-94.

33. Stankovic T, Kidd A, Sutcliffe A, McGuire G, Robinson P, Weber P, Bedenham T, Bradwell A, Easton D, Lennox G, Haites N, Byrd P, Taylor A: ATM mutations and pheotypes in ataxia-telangiectasia families in the British Isles: Expression of mutant ATM and the risk of leukemia, lymphoma and breast cancer. Am J Hum Genet 1998, 62:334-5.

34. Alter B: Cancer in Fanconi Anemia, 1927-200I. Blood 2003, 97(2):425-440.

35. Kutler D, Singh B, Satogopan J, Batish S, Berwick M, Giampietro P, Hanenberg $H$, Auerbach A: A 20-year perspective on the International Fanconi Anemia Registry (IFAR). Blood 2003, 101:1249-56.

36. Rosenberg $P$, Huang $Y$, Alter $B$ : Individualized risks of first adverse events in patients with Fanconi anemia. Blood 2004, 104:350-55.

37. Wagner J, Tolar J, Levran O, Scholl T, Deffenbaugh A, Satagopan J, Ben-Porat L, Mah K, Batish S, Kutler D, MacMillan M, Hanenberg $\mathrm{H}$, Auerbach A: Germline mutations in BRCA2: shared susceptibility to breast cancer, early onset leukemia, and Fanconi anemia. Blood 2004, 103:3226-3229.

38. Yu V, Koehler M, Steinlein C, Schmid M, Hanakari L, van Gool A, West S, Venkitaraman A: Gross chromosomal rearrangements and genetic exchange between nonhomologous chromosomes following BRCA2 inactivation. Genes Dev 2000, 14:1400-1406.

39. Levran O, Attwooll C, Henry R, Milton K, Neveling K, Rio P, Batish S, Kalb R, Velleuer E, Barral S, Ott J, Petrini J, Schindler D, Hanenberg $\mathrm{H}$, Auerbach A: The BRCAI helicase BRIPI is deficient in Fanconi anemia. Nature Genetics 2005, 37:931-3.

40. Litman R, Peng M, Jin Z, Zhang J, Powell S, Andreassen P, Cantor S: BACHI is critical for homologous recombination and appears to be the Fanconi anemia gene product FANCJ. Cancer Cell 2005, 8:255-265.

41. Luciani J, Depetris D, Usson Y, Metzler-Guillemain C, Mignon-Ravix C, Mitchell M, Megarbane A, Sarda P, Sirma H, Moncla A, Feunteun J, Mattei M-G: PML nuclear bodies are highly orgnised DNAprotein structures with a function in heterochromatin remodelling at the G2 phase. I Cell Science 2006, I 19:25 I 8-1531.

42. Xu Z-X, Timanova-Atanasova A, Zhao R-X, Chang K-S: PML colocalizes with and stabilizes the DNA damage response protein TopBPI. Mol and Cell Biol 2003, 23:4247-5256.

43. Friedman L, Thistlethwaite F, Patel K, Yu V, Lee H, Venkitaraman A, Abel K, Carlton M, Hunter S, Colledge W, Evans M, Ponder B: Thymic lymphomas in mice with a truncating muration in Brca2. Cancer Res 1998, 58: 1338-43.

44. Mak T, Hakem A, McPherson J, Shehabeldin A, Zablocki E, Migon E, Duncan G, Bouchard D, Wakeham A, Cheung A, Karaskova UJ, Sarosi
I, Squire J, Marth J, Hakem R: Brcal required for T cell lineage development but not TCR loci rearrangement. Nature Immunol 2000, I:77-82

45. Scardocci A Guidi F, D'Alou F, Gumiero D, Fabiani E, DiRuscio A Martini M, Larocca L, Zollino M, Hohaus S, Leone G, Voso M: Reduced BRCAI expression due to promoter hyermethylation in therapy-related acute myeloid leukaemia. Brit J Cancer 2006, 95: I1 108-13.

46. Risch N, McLaughlin J, Cole D, Rosen B, Bradley L, Kwan E, Jack E, Vesprini D, Kuperstein G, Abrhamson J, Fan I, Wong B, Narod S: Prevalence of Germline BRCAI and BRCA2 mutations in a population series of 649 women with ovarian cancer. $\mathrm{Am} \mathrm{J}$ Hum Genet 200I, 68:700-7I0.

47. Shih $H$, Nathanson K, Seal S, Collins N, Stratton M, Rebbeck T, Weber B: BRCAI and BRCA2 mutations in breast cancer families with multiple primary cancers. Clin Cancer Res 2000, 6:4259-64.

48. Evans H, Lewis C, Robinson D, Bell C, Moller H, Hodgson S: Cancer risks in women with 2 breast or ovarian cancers: clues to genetic cancer susceptibility. Int / Cancer 200I, 94:758-9.

49. Hemminki K, Scelo G, Boffeta P, Mellemkjaer L, Tracey E, Andersen A, Brewster D, Pukkala E, McBride M, Kliewer E, Chia K-S, PompeKirn V, Martos C, Jonasson J, Li X, Brennan P: Second primary malignancies in patients with male breast cancer. Brit J Cancer 2005, 92: 1288-92.

50. Teppo L, Pukkala E, Saxen E: Multiple cancer - an epidemiological exercise in Finland. J Natl Cancer Inst 1985, 75:207-2 I7.

51. Evans H, Lewis C, Robinson D, Bell C, Moller H, Hodgson S: Incidence of multiple primary cancers in a cohort of women diagnosed with breast cancer in southeast England. Brit J Cancer 200I, 84:435-440.

52. Ewertz M, Mouridsen H: Second cancer following cancer of the female breast in Denmark, 1943-80. Natl Cancer Inst Monogr 1985, 88:325-9.

53. Harvey E, Brinton L: Second cancer following cancer of the breast in Connecticut, 1935-1982. Natl Cancer Inst Monogr I 985 , 68:99-109.

54. Rauscher G, Sandler D, Poole C, Pankow J, Shore D, Bloomfield C, Olshan A: Is family history of breast cancer a marker of susceptibility to exposures in the incidence of de novo adult acute leukemia? Cancer Epidemiol Biomarkers Prev 2003, I 2:289-94.

55. Stewart G, Maser R, Stankovic T, Bressan D, Kaplan M, Jaspers N Raans A, Byrd P, Petrini J, Taylor M: The DNA double strand break repair gene hMREII is mutated in individuals with an Ataxia-telangiectasia like disorder. Cell 1999, 99:577-87.

56. Tauchi H, Matsuura S, Kobayashi J, Shuichi Sakamoto S, Komatsu K: Nijmegan breakage syndrome gene, NBSI, and molecular links to factors for genome stability. Oncogene 2002, 21:8967-80

57. Einarsdottir K, Humphreys K, Bonnard C, Palmgren J, lles M, Sjolan$\operatorname{der}$ A, Li Y, Chi K, Liu ET, Hall P, Liu J, Wedren S: Linkage disequilibrium mapping of CHEK2: common variation and breast cancer risk. PLOS medicine 2006, 3: el 68 .

58. Tort F, Hernandez S, Bea S, Martinez A, Esteller M, Herman J, Puig J, Camacho E, Sanchez M, Nayach I, Lopez-Guillermo A, Fernandez P, Colomer D, Hernandez L, Campo E: CHK2-decreased protein expression and infrequent genetic alterations mainly occur in aggressive types of non-Hodgkins lymphoma. Blood 2002, 100:4602-4608.

59. Yang S, Kuo C, Bisi J, Kim M: PML-dependent apoptosis after DNA damage is regulated by the checkpoint kinase hCdsI/ Chk2. Nature Cell Biol 2002, 4:865-6I.

60. Dellaire G, Ching R, Ahmed K, Jalali F, Tse K, Bristow R: Promyelocytic leukemia nuclear bodies behave as DNA damage sensors whose respone to DNA double-strand breaks is regulated by NBSI and the kinases ATM, Chkw and ATR. Journal Cell Biol 2006, 175:55-66.

6I. Luciani J, Depris D, Usson Y, Metzler-Guillemain C, Mignon-Ravix C, Mitchell M, Megarbane A, Sarda P, Sirma H, Moncla A, Feunteun J, Mattei M: PML nulcear bodies are highly organised DNA-Protein structures with a function in heterochromatin remodelling at the G2 phase. J Cell Sci 2006, I I 9:25 I8-3I.

62. Speck Nm, Gilliland $\mathrm{D}$ : Core-binding factors in haematopoiesis and leukemia. Nature Rev Cancer 2002, 2:502-5I3. 
63. Rosenbauer F, Tenen $\mathrm{D}$ : Transcription factors in myeloid development: balancing differentiation with transformation. Nature Rev Cancer 2007, 7(2): 105-II 7.

64. Garraway L, Sellers W: Lineage dependency and lineage survival oncogenes in human cancer. Nature Rev Cancer 2006, 6:593-602.

65. Narducci M, Virgilio L, Isobe M, Stoppacciaro A, Elli R, Fiorilli M, Carbonari M, Antonelli A, Chessa L, Croce C, Russo G: TCLI oncogene activation in preleukemic T-cells from a case of Ataxiatelangiectasia. Blood 1996, 86:2358-2364.

66. Wildonger J, Mann R: The t(8:2I) translocation converts AMLI into a constitutive transcriptional repressor. Development 2005, 132:2263-2272.

67. Duprez E, Wagner K, Koch H, Tenen D: C/EBPbeta: a major PML-RARA-responsive gene in retinoic acid-induced differentiation of APL cells. The EMBO Journal 2003, 22:5806-16.

68. Strick R, Zhang Y, Emmanuel N, Strissel P: Common structures at breakpoint cluster regions may lead to chromosomal translocations found in chronic and acute leukemias. Hum Genet 2006, I 1 9:479-85.

69. Cuneo A, Bigoni R, Negrini M, Bulirich F, Veronese M, Roberti M, Bardi A, et al.: Cytogenetic and Interphase Cytogenetic Characterization of Atypical Chronic Lymphocytic Leukemia Carrying BCLI Translocation. Cancer Res 1997, 57: I 44-50.

70. Sarasworthy $R$, Natarajan A: Frequencies of $x$-ray induced chromosome aberrations in lymphocytes of xeroderma pigmentosum and Fanconi anemia patients estimated by Giemsa and fluorescence in situ hybridization staining techniques. Genetics and Mol Biol 2000, 23:893-99.

71. Raynaud S, Baens M, Grosgeorge J, Rodgers K, Reid C, Dainton M, Dyer M, Fuzibet J, Gratecos N, Taillan B, Ayraud N, Marynen P: Fluorescence in situ hybridization analysis of $t(3 ; \mid 2) q 26 ; p \mid 3)$ : a recurring chromosomal abnormality involving the TEL gene (ETV6) in myelodysplastic syndromes. Blood 1998, 88:682-89.

72. Jolkowska J, Witt M: The Evl-I gene - its role in pathogenesis of human leukemias. Leukemia research 2000, 24:553-8.

73. Zody M, Garber G, Adams D, Sharpe T, Harrow J, Lupski J, Nicholson C, Searle S, Wilming L, Young S, Abouelleil A, Allen N, Bi W, Bloom T, Borowsky M, Bugalter B, Butler J, Chang J, Chen C-K, Cook A, Corum G, Cuomo C, de Jong P, DeCaprio D, Dewar K, FitzGerald M, Gilbert G, Gibson R, Gnerre S, Goldstein S, et al.: DNA sequence of human chromosome 17 and analysis of rearrangement in the human lineage. Nature 2006, 440:1045-1049.

74. Popovici C, Basset C, Bertucci F, Orsetti B, Adelaide J, Mozziconacci M], Conte N, Murati A Ginestier C, Charafe-Jauffret E, Ethier SP, Lafage-Pochitaloff M, Theillet $C$, Birnbaum D, Chaffanet M: Reciprocal translocations in breast tumor cell lines: cloning of a $t(3 ; 20)$ that targets the FHIT gene. Genes Chromosomes Cancer 2002, 35:204-18.

75. Pole J, Courtay-Cahan C, Garcia M, Blood K, Cooke S, Alsop A, Tse $D$, Caldas $C$, Edwards $P$ : High resolution analysis of chromosome rearrangements on $8 \mathrm{p}$ in breast, colon and pancreatic cancer reveals a complex pattern of loss, gain and translocation. Oncogene 2006, 25(4I):5693-706.

76. DePinho R: The age of cancer. Nature 2000, 408:248-254.

77. Ponder B: Cancer Genetics. Nature 200I, 4I I:336-34I.

\section{Pre-publication history}

The pre-publication history for this paper can be accessed here:

http://www.biomedcentral.com/1471-2407/7/152/pre pub

\section{Publish with Bio Med Central and every scientist can read your work free of charge}

"BioMed Central will be the most significant development for disseminating the results of biomedical research in our lifetime. "

Sir Paul Nurse, Cancer Research UK

Your research papers will be:

- available free of charge to the entire biomedical community

- peer reviewed and published immediately upon acceptance

- cited in PubMed and archived on PubMed Central

- yours - you keep the copyright

Submit your manuscript here:

http://www.biomedcentral.com/info/publishing_adv.asp
BiolMedcentral 